\title{
Evaluation of two wind flow models for wind resource assessment for a site
}

\author{
Vilas Warudkar ${ }^{1}$, Pramod Sharma ${ }^{2}$, and Siraj Ahmed ${ }^{3}$ \\ ${ }^{1}$ Associate Professor, Department of Mechanical Engineering, MANIT, Bhopal (M.P.), India \\ ${ }^{2}$ Research Scholar, Department of Mechanical Engineering, MANIT, Bhopal (M.P.), India \\ ${ }^{3}$ Professor, Department of Mechanical Engineering, MANIT, Bhopal (M.P.), India
}

\begin{abstract}
There are different numerical wind flow models are existing to simulate atmosphere flows. The conventional approach has been relying on Jackson- Hunt linear wind flow models, computational fluid dynamics and Reynolds- averaged Navier Stokes models has been explored in research to predict wind resource for a site. The present work aims to analyze the performance of two wind flow models to predict the variation of wind speed. The two are 1) WAsP (linear Jackson- Hunt model) and 2) CFD/RANS models. The wind flow numerical models are compared with high-quality measurements from single meteorological mast. It has been found that the root meant square error for the WAsP model is $23 \%$ greater than the Reynolds- averaged Navier Stokes model.
\end{abstract}

\section{Introduction}

A detailed understanding of the design of wind project is necessary to correct prediction of wind energy potential for a site. Currently, different numerical wind models are available for estimating wind power production. The two wind flow models based on the theory of Jackson- Hunt such as WAsP [1-2] and MSFD [3] are widely used to predict wind rose, wind shear, wind speed, and other wind characteristics. These wind flow models are based on the theory of Jackson and Hunt [4]. Reynoldsaveraged Navier- Stokes models are replacing as an alternative to WAsP wind flow models for wind energy applications. It solves the complex conservation of massmomentum equation, but the energy equation is not involved in the equations.

They run faster on a personal computer due to simplifying assumptions of steady state. [5] earlier research predicts that Reynolds- averaged Navier Stokes numerical models can forecast wind speed better than the industry standard WAsP model. In this paper, two numerical wind resource assessment models are compared based on the measurements of a single anemometer.

\section{Methodology}

The location of the site is shown in Fig 1. The terrain ruggedness index (RIX) [6] at the masts is around $0-8 \%$. The site is located at Maulana Azad National Institute of Technology (MANIT Bhopal), is, in Bhopal, Madhya Pradesh, India. The institute has a total covered area of 650 acres $\left(2.6 \mathrm{~km}^{2}\right)$. Madhya Pradesh state has a total installed capacity@50m and@80m is 920 MW and 2931 MW respectively as on 2016-2017. At the $100 \mathrm{~m}$ height, the state has a capacity of $8259 \mathrm{MW}$. The site details and 3D grid map of the MANIT have been shown in Fig.1, Fig.2 and Table 1. The digital elevation and roughness map of the site has been shown in Fig. 3 and Fig. 4 respectively.

Table 1. Site details

\begin{tabular}{|c|c|}
\hline Place & $\begin{array}{c}\text { Detailed Wind Data of MPSTEP, } \\
\text { MANIT, Bhopal, India }\end{array}$ \\
\hline Site Coordinates & $\begin{array}{c}\text { Latitude: } 23^{\circ} 12^{\prime} 25^{\prime}, \mathrm{N}, \text { Longitude: } \\
77^{\circ} 24^{\prime} 29^{\prime}, \mathrm{E}\end{array}$ \\
\hline $\begin{array}{l}\text { Height above mean } \\
\text { sea level }\end{array}$ & $537 \mathrm{~m}$ \\
\hline Duration & $\begin{array}{l}\text { One Year } 10 \text { min. Time series wind } \\
\text { data }\end{array}$ \\
\hline Instrument & $\begin{array}{l}\text { NRG Systems, Anemometer, } \\
\text { Direction Sensor and Data Logger on } \\
25 \mathrm{~m} \text { Tower }\end{array}$ \\
\hline
\end{tabular}

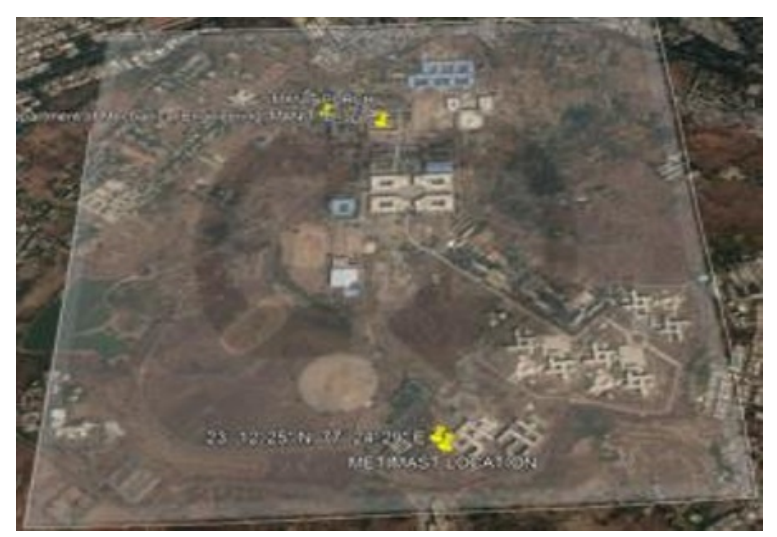

Fig. 1. Location of met mast 


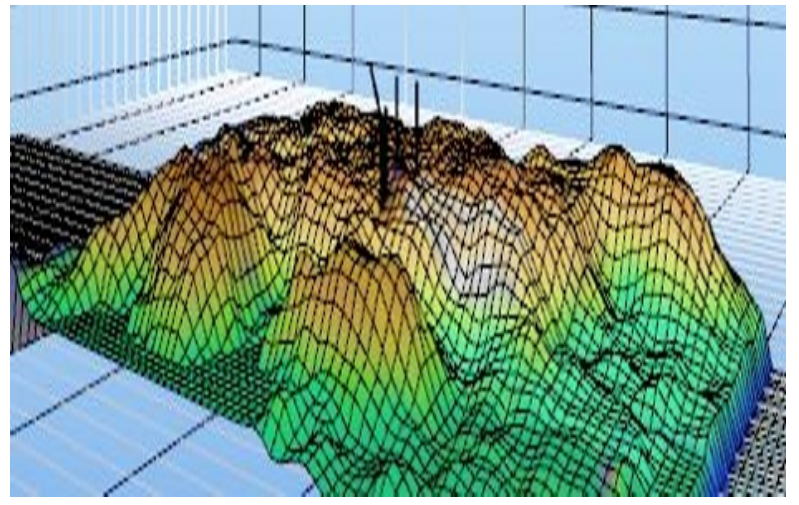

Fig. 2. 3D terrain grid profile

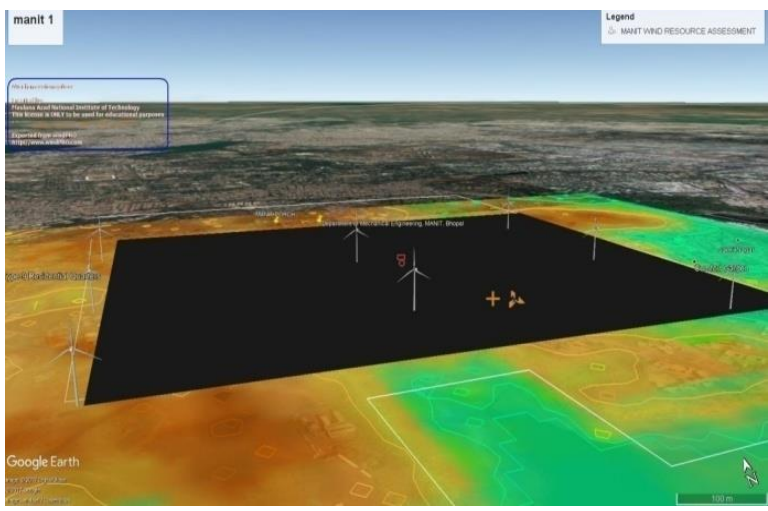

Fig. 3. Wind farm image for a site

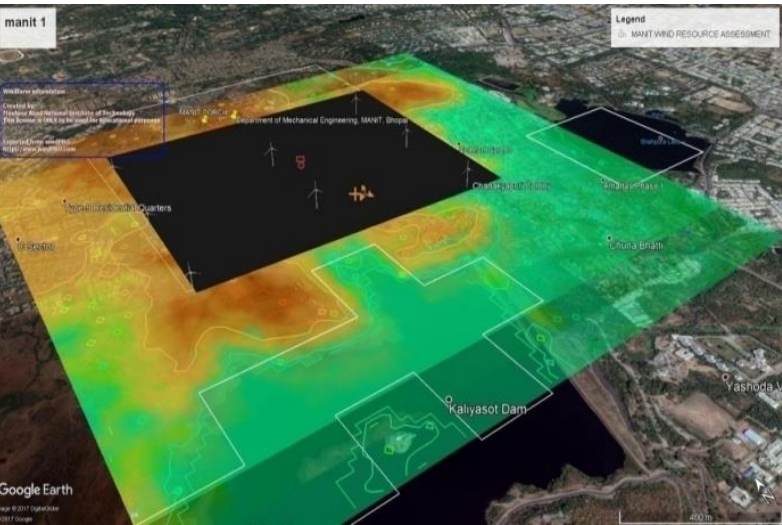

Fig. 4. Wind farm image for a site

With the help, an experienced wind data analyst, the data obtained from met masts are filtered and screened. The filtered data were taken into account the effects of the tower, turbulence and dry friction whip. Also, measurement correlate predict techniques were implemented to the data measurements systems [7]. Generally, it is a recommended practice in the wind industry and organization to commission higher towers with anemometers and wind vane and record the site data for a year or more. The correction in climate was done because of the filtering of mean wind speeds between the site and a mast to a typical period. Once the measured wind data from anemometers and wind vanes are filtered in this manner, the met mast time series data were converted to a binned by the frequency of wind directions and speeds. The wind flow models can use the same file either as in initial conditions and post-processor.

\subsection{Jackson-hunt wind flow numerical model}

Wind Atlas Analysis Program developed at Riso Denmark technical university based on the linear theory of Jackson-Hunt. The Navier-Stokes equations had solved using this model under various assumptions: first order closure and steady state. In this model high density forest areas are modelled by taking suitable assumptions the surface roughness length to canopy height ratio of 0.075 . The same digital elevation and roughness maps without displacement heights are used, in order to compare six numerical wind flow models. At higher altitudes, there is a less effect of the displacement ratio on wind speeds. The primary inputs to predict wind resource for a site is the terrain roughness, digital elevation, and binned file of wind speeds and directions form meteorological masts. It solves the simplified version of Navier-Stokes equations for each direction sector, like most of the microscale wind flow models. The wind resource grid files are created in the WAsP 11 with a grid spacing of $60 \mathrm{~m}$. In order to improve the precision of the prediction, researchers have done the corrections based on the previous knowledge or RIX [6].

\subsection{Reynolds- averaged Navier- Stokes Numerical model}

Metodyn had developed, the computational fluid dynamics/Reynolds- averaged Navier Stokes model, Metodyn WT. The non-linear partial differentiation momentum equation is solved with the MIGAL solver. This Reynolds- averaged Navier Stokes model assumes steady state and incompressible flow of the wind, based on the k-1 turbulence closure model given by [8] and [9]. It take account partially thermal stability effects using attuned turbulence length scale in the turbulent energy equation, without solving the conservation of energy equation. There are 10 number of thermal stability classes are present in the given model. But, it could not be possible to inculcate the stability effect at the site, due to the absence of temperature data from met masts.

The primary inputs to this model are usually the surface roughness, a logarithmic wind speed profile, and an Ekman profile for the remaining of the boundary layer. A typical diagram of the Metodyn WT process is shown in Fig. 5. It calculates the mean wind speed for each directional sector independently as for most of the micoscale models. This model calculates the directional speed ration at each mast and point during postprocessing. 


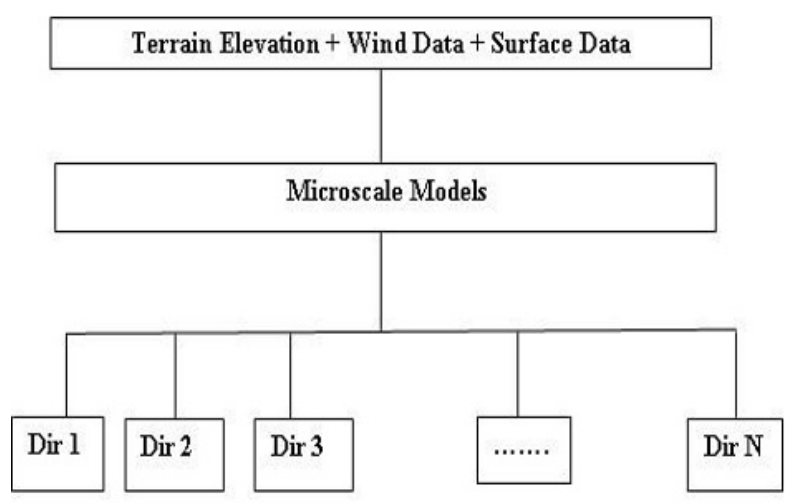

Fig. 5. A diagram of the microscale modelling process

\subsection{Runtime}

The model runtimes were compared by simulating with each model over an $8 \mathrm{~km} \mathrm{X} 8 \mathrm{~km}$ domain with a met masts. The diagnostic microscale models (WAsP an RANS) are run in a different way. The models were run over 12 different direction sectors (Table 2). The WAsP model takes a longer runtime than CFD model. It should be noted that WAsP was designed to calculate the wind speeds at independent points.

Table 2. Approximate runtimes in hours for the different numerical models for a typical $8 \mathrm{~km} \mathrm{X} 8 \mathrm{~km}$ domain with two masts.

\begin{tabular}{|c|c|c|}
\hline Model & $\begin{array}{c}\text { WAsP } \\
(\mathbf{5 0 m})\end{array}$ & $\begin{array}{c}\text { CFD/RANS } \\
(\mathbf{5 0 m})\end{array}$ \\
\hline Time & 6 & 3 \\
\hline Unit & - & Per direction \\
\hline
\end{tabular}

\subsection{Metrics error}

The model runtimes were compared by simulating with each model over an $8 \mathrm{~km}$ X $8 \mathrm{~km}$ domain with a met mast. The metrics of error for each model is the normalized bias, the root mean square error (RMSE), normalized root meant square error (NRMSE), index of agreement (IA) and normalized error (NE) between the predicted and observed mean wind speeds, defined as follows:

$$
\text { Normalized bias }=\frac{1}{\mathrm{~N}} \frac{\sum_{\mathrm{i}=1}^{\mathrm{N}} \sum_{\mathrm{j}=1 \cdot}^{\mathrm{N}} \cdot\left(\mathrm{O}_{\mathrm{i}, \mathrm{j}}-\mathrm{P}_{\mathrm{i}}\right)}{\sqrt{\overline{\mathrm{O}_{1,3}, \cdot \overline{\mathrm{P}_{1}}}}}
$$

Root mean square error $=\sqrt{\frac{1}{N}} \sum_{i=1}^{N} \sum_{\substack{j=1 \\ j \neq 1}}^{N} \cdot\left(O_{i, j}-P_{i}\right)^{2}$

normalized root mean square error $=\mathrm{RMSE} / \sqrt{\overline{\mathrm{O}_{1, \mathrm{j}}} \cdot \overline{\mathrm{P}_{1}}}$

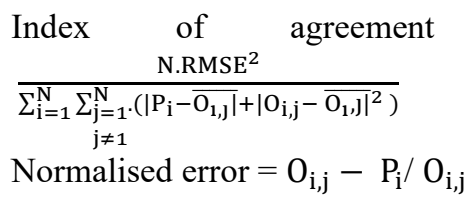

Where $\mathrm{N}$ is the number of masts, $\mathrm{O}_{\mathrm{i}, \mathrm{j}}$ is predicted mean wind speed at mast $i$ based on the reference mast $j$ and , $P_{i}$ is the observed mean speed at mast $i, \overline{O_{1}}, j$ is predicted mean wind speed at mast $i$ based on the reference mast $j$ and $\bar{P}_{1}$ is the mean observed mean speed at mast i. Each numerical wind flow model outputs the mean wind speed by direction sector in a WRG file. The met mast is used to create WRG file is called the reference mast.

\section{Results and discussion}

\subsection{Local wind climates}

It is clear from diurnal variation of mean wind speed and wind shear that the stability criteria of the atmosphere are quite different between day and night. The wind shear exponent was calculated using anemometer measurements as: [7],

$\frac{\mathrm{U}_{1}}{\mathrm{U}_{2}}=\left(\frac{\mathrm{h}_{1}}{\mathrm{~h}_{2}}\right)^{\alpha}$

where $\mathrm{h} 1$ and $\mathrm{h} 2$ are the heights of the anemometers on a mast and $\mathrm{U} 1$ and $\mathrm{U} 2$ are the measured wind speeds at the corresponding heights $h_{1}$ and $h_{2}$. Mean wind shear exponents which vary diurnally were calculated between the lower and upper levels on the mast, i.e., between 20 $\mathrm{m}$ and $80 \mathrm{~m}$ for the site. The wind shear exponents are considerably higher at night than during the day as shown in Fig. 6 and Fig. 7. It is due to the common experience that over land, radiative cooling at night produces a stable layer whereas heating from the sun during the day tends to create a convective layer.

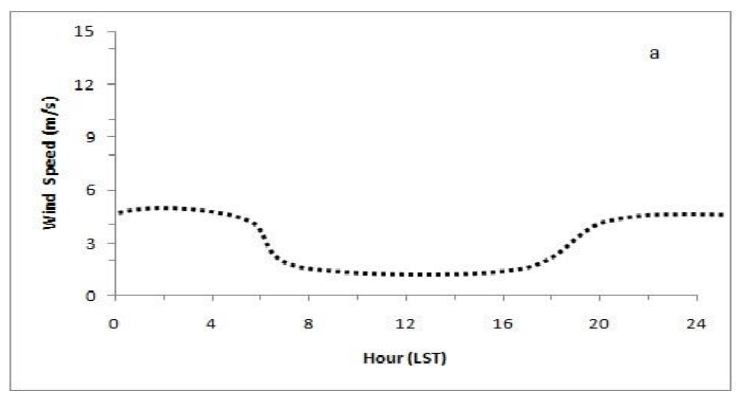

Fig .6. Diurnal wind speed variation

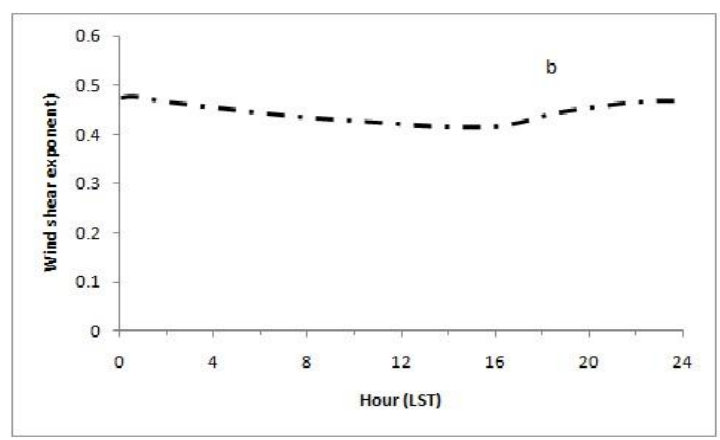

Fig .7. Diurnal wind speed variation 


\subsection{Error statistics (Validation)}

All two numerical models described earlier were run at the single validation sites using the same two met mast data, surface roughness maps, and terrain elevation data.. At the validation site, the error statistics- the normalized bias, RMSE, NRMSE, IA, and NE were calculated from equations (1), (2), (3), (4), and (5) using the modeled and observed mean wind speeds.

Table 3. Validation of the modeled wind speed at $80 \mathrm{~m}$ above ground level, using the Normalised Bias, Root mean square error, Normalised Root mean square error, Index of agreement and normalized error calculations from equations (4) - (10)

\begin{tabular}{|c|c|c|c|c|c|}
\hline Terrain & \multicolumn{5}{|c|}{ Opmplex } \\
\hline Land Cover & \multicolumn{5}{|c|}{} \\
\hline $\begin{array}{c}\text { Number of } \\
\text { Masts }\end{array}$ & NB & RMSE & NRMSE & IA & NE \\
\hline WAsP & 0.00 & 0.21 & 0.25 & 0.88 & 0.03 \\
\hline
\end{tabular}

where $\mathrm{k}$ shows the site and $\mathrm{N}$ is the total no. of masts at site k. All results are shown in table 3. The RMSE, NRMSE, IA, and NE reflect the possible errors both in the observed mean wind speeds and model outputs. The ambiguity in the observed mean wind speeds considering tower effects, turbulence, height, and all other factors, is estimated to be about $3.5 \%$.

$$
\begin{aligned}
& \text { Bias }_{\text {tot }}=\frac{\sum_{\mathrm{k}=1}^{\mathrm{S}} \mathrm{N}_{\mathrm{k}} \cdot \mathrm{Bias}_{\mathrm{k}}}{\sum_{\mathrm{k}=1}^{\mathrm{S} \mathrm{N}_{\mathrm{k}}}} \\
& \text { RMSE }_{\text {tot }}=\sqrt{\frac{\sum_{\mathrm{k}=1}^{\mathrm{S}} \mathrm{N}_{\mathrm{k}} \cdot \mathrm{RMSE}^{2}}{\sum_{\mathrm{k}=1}^{\mathrm{S} \mathrm{N}_{\mathrm{k}}}}}
\end{aligned}
$$

The normalized bias is usually $0 \%$ for two numerical wind flow models. The error in predicting the mean wind speed at mast $i$ using $j$ as a reference (i.e. $\mathrm{O}_{\mathrm{i}, \mathrm{j}}-\mathrm{P}_{\mathrm{i}}$ ) should normally be offset by the error of predicted the speed at mast $\mathrm{j}$ using $\mathrm{i}$ mast as a reference (i.e. $\mathrm{O}_{\mathrm{j}, \mathrm{i}}-\mathrm{P}_{\mathrm{j}}$ ).

\section{Conclusion}

In this paper two wind flow models have been studied using two metrological masts having different wind weather and surface conditions. The same met mast wind data, digital elevation map and land cover roughness maps are used for all wind flow numerical models. The wind data measurements at the site suggest that the thermal effects have major impacts on the wind speeds within the first $100 \mathrm{~m}$ of the boundary layer.

The normalized bias is usually close to $0 \%$ for all the models. Out of which more interest are on the root mean square error, normalised error and normalised root mean square error. It has been found the RMSE for the WAsP model based on Jackson-Hunt theory was $23 \%$ greater than the Reynold-Averged Navier-Stokes models.

\section{References}

1. Troen I, Petersen EL. European wind atlas. Report from the Risø National Laboratory, Roskilde, Denmark, 1989.

2. Troen I. A High-resolution spectral model for flow in complex terrain. Proceedings from the 9th Symposium on Turbulence and Diffusion, Roskilde, Denmark, 1990.

3. Beljaars ACM, Walmsley JL, Taylor PA. A mixed spectral finite-difference model for neutrally stratified boundary-layer flow over roughness changes and topography. Boundary-Layer Meteorology. 1987; 38: 273-303.

4. Jackson P, Hunt JCR. Turbulent wind flow over a low hill. Quarterly Journal of Royal Meteorological Society. 1975;101: 929-955.

5. Bitsuamlak GT, Stathopoulos T, Bédard C. Numerical evaluation of wind flow over complex terrain: a review. Journal of Aerospace Engineering. 2004; 17: 135-145.

6. Mortensen NG, Bowen AJ, Antoniou I. Improving WAsP predictions in (too) complex terrain. Proceedings from EWEC, Brussels, Belgium, 2008.

7. Brower. Wind resource assessment: a practical guide to developing a wind project.Wiley editions: New York, 2012; 280.

8. Yamada T. Simulations of nocturnal drainage flows by a q21 turbulence closure model. Journal of Atmospheric Sciences .1983; 40: 91-106.

9. Arritt RW. The effect of water surface boundary layers. Boundary-Layer Meteorology. 1987; 40: 101-125. 